\title{
020 selection mode portrait and optimization for railway service enterprises based on $K$-means
}

\author{
Changsuo Sun ${ }^{1} \cdot{\text { Long } \mathrm{Ye}^{1} \cdot \mathrm{Na} \text { Zhang }}^{1}$
}

Received: 18 November 2020 / Accepted: 10 April 2021

(c) The Author(s) 2021

\begin{abstract}
Establishing a platform successfully is just the basis for railway service companies to meet the demands of online to offline $(\mathrm{O} 2 \mathrm{O})$ supply chain services. In this paper, the $K$-means algorithm is first used to construct the user segmentation model of railway service companies and the AISAS (Attention-Interest-Search-Action-Share) method is used to establish the evaluation $\mathrm{O} 2 \mathrm{O}$ model. According to this result, we propose four modes to establish $\mathrm{O} 2 \mathrm{O}$ supply chain service platform for railway enterprise, which are self-built and self-operated (SBSO, Mode1), commissioned construction and self-operated (CCSO, Mode2), self-built and commissioned operation (SBCO, Mode3), commissioned construction and commissioned operation (CCCO, Mode4). By comparing the advantages and disadvantages of the four modes, the results illustrate the optimal model is impacted by the nature of the platform's operating products and the operating capabilities of the partners. The railway service enterprise needs to transform the traditional multi-level management model into the flat model to adapt the $\mathrm{O} 2 \mathrm{O}$ supply chain strategies.
\end{abstract}

Keywords Railway service company $\cdot \mathrm{O} 2 \mathrm{O} \cdot$ Supply chain $\cdot$ Optimization

\section{Introduction}

With the advent of the "Internet + " era, making passengers can enjoy timely and efficient railway and supply chain services without leaving home has generated a higher demand, $\mathrm{O} 2 \mathrm{O}$ has become one of the most valuable transformations of the railway service enterprises development path. More recently, COVID-19 related travel restrictions have led many services to quickly transition to online [1]. It also accelerates the pace of $\mathrm{O} 2 \mathrm{O}$ change for railway service enterprises to adopt $\mathrm{O} 2 \mathrm{O}$ strategies, either completely or partially in collaboration with third-party platforms.

The railway supply chain $\mathrm{O} 2 \mathrm{O}$ model has already seen the beginning in China. Shandong Jinan Railway Station has accelerated the construction of service system, initially

Na Zhang

zhangna@bjtu.edu.cn

Changsuo Sun

09113178@bjtu.edu.cn

Long Ye

yelong@bjtu.edu.cn

1 School of Economics and Management, Beijing Jiaotong University, Beijing 100044, China perfected the service system of "one center, two channels and one platform", and built up an $\mathrm{O} 2 \mathrm{O}$ model of passenger service. One center is the customer service center; two channels, one channel is the online microblogging, WeChat and telephone reservation service, the other channel is the offline love channel. Through official microblogging, WeChat groups, friends' circles and other forms, the train station uses the internet to "cross-pollinate" with the station's passenger sections and all the larger stations across the country, and establishes cooperation with long-distance bus, aviation and other transportation departments and other public welfare organizations to realize information sharing and collect information flow on passenger needs. The train station has built the customer service center into a threedimensional operation platform that integrates the service center, comprehensive center and emergency center, and provides special services, such as key passenger ticket windows, service posts, inbound passageways, customer service centers, passenger ticket-cutting gates, one-key help system on the platform and transit area at the exit gate, through direct-dial telephone, love relay cards and "one-to-one private customized services". "Open up the connection, to achieve key passenger services" final closed loop. In the railway supply chain $\mathrm{O} 2 \mathrm{O}$ model, it can also provide a richer 
range of services. For example, passengers can also place orders in the app to provide corresponding products at stopping points during the journey. The railway $\mathrm{O} 2 \mathrm{O}$ model has great potential for market broadening and is deepening and diversifying towards a multi-level, multi-dimensional complex ecosystem industry.

The establishment of $\mathrm{O} 2 \mathrm{O}$ platform is the foundation for railway service enterprises is the first challenge, and then satisfying the needs of passengers by online is another important issue faced by railway service enterprises. The studies will propose four different model to construct platform and analyze their comparative advantages, and then select the most appropriate construction mode. In fact, with the advancement of technology, passengers' time is gradually fragmented and their demand for products/services becomes more and more personalized. When a wide variety of apps are available, railway service companies need to change their organizational structure to seize users' time and smoothly deliver their products/services to the target customers. Furthermore, $\mathrm{O} 2 \mathrm{O}$ may prompt railway service companies transform the traditional multi-level management model into a flat model, in which setting up operations departments or outsourcing operations could ensure the normal functioning of the entire $\mathrm{O} 2 \mathrm{O}$ supply chain services.

The rest of the paper is organized as follows: We first conduct a comprehensive literature review in Sect. Literature review. In Sect. Selection mode portrait, an analytical portrait model and the mathematical model are proposed that forms the basis of the research problem. In Sect. Modeling, solution and analysis, we compare the four modes and draws corresponding conclusions. In Sect. Analysis of the four modes, we verify the model through numerical simulation. Section Numerical simulation concludes findings and gives practical suggestions.

\section{Literature review}

At present, the $\mathrm{O} 2 \mathrm{O}$ model is developing rapidly in the retail, service and other industries, and the railway service industry has just started, and few researchers have paid attention to the development of $\mathrm{O} 2 \mathrm{O}$ in railway service enterprises. In this paper, we mainly summarize the existing research progress from the $\mathrm{O} 2 \mathrm{O}$ business model and service supply chain.

\section{0 and business mode portrait}

Rampell argued that the core of the $\mathrm{O} 2 \mathrm{O}$ business model is to search for customers online for offline purchases and to combine the payment model with offline store traffic, and draws on e-commerce B2B, B2C and other common naming abbreviations such as $\mathrm{O} 2 \mathrm{O}$ [2]. Fang argued that today's
$\mathrm{O} 2 \mathrm{O}$ has long since ceased to be a separate online one offline concept, and has added more operational methods, but $\mathrm{O} 2 \mathrm{O}$ commerce itself is still oriented to the field of life consumption [3].

The development of $\mathrm{O} 2 \mathrm{O}$ business model in China originated from the emergence of online group buying model [4], and before 2010, Ctrip.com was the first $\mathrm{O} 2 \mathrm{O}$ business model in China, represented by the intermediary model of online solicitation of customers and offline acquisition of travel company services provided to customers [5]. According to $\mathrm{Yu}$ [6], community $\mathrm{O} 2 \mathrm{O}$ is a mobile Internet-based platform that integrates online and offline resources to provide a "last mile" service system for community residents, while Shen [7] believed that the unique attributes of the property industry give it a natural soil advantage over other traditional industries. Under such a background, the property industry has also set off a wave of community $\mathrm{O} 2 \mathrm{O}$ business model change within the industry. More and more property service companies are beginning to rethink the value of travelers and actively participate in community living $\mathrm{O} 2 \mathrm{O}$ construction while upgrading and optimizing basic property services to deeply explore and enhance the value of property services [8].

Most scholars are optimistic about the driving effect of $\mathrm{O} 2 \mathrm{O}$ model on the existing market. Zhang and Moonargued that the efficient and convenient nature of $\mathrm{O} 2 \mathrm{O}$ business model is attractive to both buyers and sellers and is a win-win-win model for merchants, customers, and potential participants [9]. Won et al. pointed out that $\mathrm{O} 2 \mathrm{O}$ platforms can meet the diverse needs of buyers and sellers and improve the efficiency of transactions, and mobile marketing is the key to the development of this model [10]. Shenet al. used empirical research methods to explore the differences between the $\mathrm{O} 2 \mathrm{O}$ model and the traditional model, that consumers online good word-of-mouth feedback, as well as learning from other successful business models can help strengthen the expansion of online and offline platform business and profitability, but also increase the industry competition [11]. Xu believed that with the rapid development of mobile Internet, the emergence of smartphones, tablets and other mobile terminals has changed people's lives, shopping patterns and consumption habits [12]. Hui also analyzed the future opportunities and challenges of m-commerce by investigating the background and current situation of m-commerce and $\mathrm{O} 2 \mathrm{O}$ business models [13]. Xing et al. [14], Wan [15] pointed out that marketing, transaction and consumption experience are the most active basic business in the business model. Behavior, using these 3 behavioral coordinates to define $\mathrm{O} 2 \mathrm{O}$, the following 4 types of business models can be derived: online merchant transactions-offline consumer experience, online shared transactions -offline usage experience (sharing economy model), offline merchant marketing-online transactions to place orders, offline 
merchant marketing-order online transactions and synchronize online and offline.

\section{0 and supply chain optimization}

Gao and Su analyzed the impact of "buy online, pick up offline" and developed a programmatic model with online and offline channels based on consumers' channel choice preferences [16]. Products, but purchased online at lower retail prices, studied two types of online and brick-and-mortar retailers and analyzed the price matching problem [17]. Tsay and Agrawal studied the impact of channel conflict on consumer demand in an e-commerce environment and classified channel sales strategies into direct sales, sales through distributors and both combined with sales while developing incentive programs [18]. Ullrich and Transche discussed the relationship between supply-supply mismatches (DSM) and stock returns and performed an empirical analysis, and DSM reduced sales growth rates and profitability [19]. Cao et al. found that manufacturers could using their own retail stores to sell more products to increase market demand, if manufacturers sell highly substitutable products, they should use independent retailers and consider the cost of product returns. Chocarro et al. discussed the market demand and channel selection issues for online and offline retail stores [20]. Balakrishnan et al. analyzed the market demand and channel selection issues for online and offline retail stores in a demand uncertainty scenario, the influence of browsing and switching behavior on online pricing decisions. Jain et al. [21] studied the problem of optimal decision making based on the capabilities of supply chain members and service quality for different products when considering integrated or decentralized situations. After-sales service framework and its application. Resta et al. [22] discussed the issue of optimizing supply chain management by optimizing product design and improving the service quality. Caggiano et al. [23] studied the issue of multi-product, multi-stage supply chain to improve supply chain efficiency by optimizing consumer-facing service quality and inventory. Dan et al. pointed out that although $\mathrm{O} 2 \mathrm{O}$ promotes the change of e-commerce, it brings various drawbacks such as unequal information, questionable authenticity of goods, and the quality of service is also not guaranteed [24]. O2O e-commerce model may overturn the original organizational structure, the original single organizational structure, will evolve into multiple divisions or multiple departments coordinated development [25].

Nowadays, the research of $\mathrm{O} 2 \mathrm{O}$ supply chain services of railway is still in a blank stage, and the main reason may be the reform hysteresis of state-owned railway services enterprise facing the shock of $\mathrm{O} 2 \mathrm{O}$ business model. However, with the maturity of technology and the introduction of relevant policies, it is an inevitable for railway service enterprises to reform. In this case, the study was conducted with an assumption scenario that railway service enterprises are seeking for $\mathrm{O} 2 \mathrm{O}$ reform, which faces the strategic decision of building an $\mathrm{O} 2 \mathrm{O}$ supply chain service platform either self-built or entrusted to a third party and operating mode self-operated or entrusted to a third party. And it points out possible results for railway services company after reforming.

\section{Selection mode portrait}

\section{K-means method}

We use the vector $V=\left(V_{1}, V_{2}, \ldots, V_{K}\right)^{T}$ to depict the Euclidean metric for computing the distance between points and cluster centers in K-means algorithm. As a result, K-means can find spherical or ball-shaped clusters by data analysis. Square sum of error is often used as the criterion function for K-means clustering, so we use the definition:

$E=\sum_{i=1}^{k} \sum_{p \in X_{i}}\left\|p-m_{i}\right\|^{2}$

where $m_{i}$ is the mean, $p$ means the spatial spot.

The initial value vectors $V_{A} V_{B} V_{C}$ could be gradually reduced, so the corresponding minimum values could be got, respectively. And among them, the value at point $B$ is the global minimum, the values at point $\mathrm{A}$ and $\mathrm{C}$ are the local minimum (see Fig. 1).

We set $X=\left\{x_{i}\right\}, i=1, \ldots, n$ clustered into a set of $K$ clusters, and $C=\left\{c_{k}, k=1, \ldots, K\right\}$. $K$-means is used to find the value at point $\mathrm{B}$ which is the global minimum. $z_{j}$ is the mean of cluster $c_{k}$, and the squared error between $z_{j}$ and the points $c_{k}$ is:

$J\left(c_{k}\right)=\sum_{x_{i} \in c_{k}}\left\|x_{i}-z_{j}\right\|^{2}$

$\mathrm{K}$-means is used to minimize the sum of the squared error in all $\mathrm{K}$ clusters.

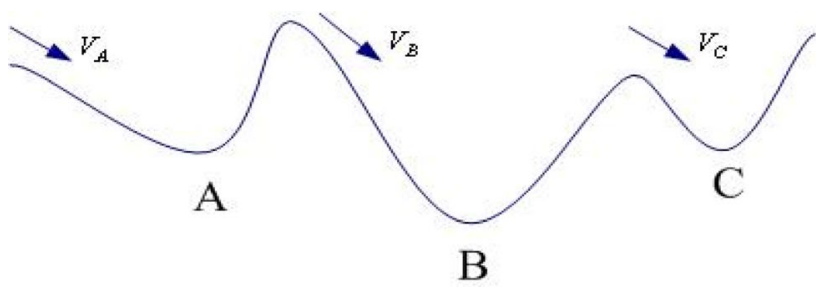

Fig. 1 The local minimum and whole minimum

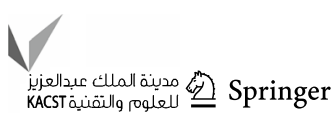


$J_{C}(I)=\sum_{j=1}^{k} \sum_{k=1}^{n_{j}}\left\|x_{k}^{(j)}-Z_{j}(I)\right\|^{2}$

The main steps of K-means algorithm are as follows:

1. Given data set $n$, let $I=1, Z_{j}(I), j=1,2,3, \ldots, k$ is selected as the initial clustering centers;

2. Calculate the distance between all points and clustering center:

$$
\begin{aligned}
& \quad D\left(x_{i}, Z_{j}(I)\right), i=1,2,3, \ldots, n, j=1,2,3, \ldots, k, \\
& \quad \text { If } D\left(x_{i}, Z_{k}(I)\right)=\min \left\{D\left(x_{i}, Z_{j}(I)\right), j=1,2,3, \ldots, k\right\}, \\
& \text { then } x_{i} \in w_{k} ;
\end{aligned}
$$

3. Calculate the error function $J_{C}$;

4. If $\left|J_{C}(I)-J_{C}(I-1)\right| \triangleleft \xi$, the algorithm ends; otherwise, the algorithm finds new clustering centers:

$$
Z_{j}(I)=\frac{1}{n} \sum_{i=1}^{n_{j}} x_{i}^{(j)}, \quad j=1,2,3, \ldots, k
$$

The iteration of K-means is showed in Fig. 2.

AISAS (Attention-Interest-Search-Action-Share), consumers gradually change from passively receiving product information and marketing propaganda to actively acquiring and cognizing, AISAS emphasizes information collection after consumers pay attention to products and generate interest (AISAS considers information gathering and information sharing as two important aspects, both of which are inseparable from consumers' use of the Internet. The Internet provides consumers with the opportunity to actively access information, so that they can obtain detailed professional information from multiple sources and make relatively "informed" purchases. However, under the AISAS model, the core driver of marketing activities is still advertising, and the keywords of marketing activities are still brand display and impression, but there are more click, action, Landing page conversion and other such effect dimensions, and the relationship between brands and users has started to Although the relationship between brands and users has started to interact, it is only based on the simple fragmented feedback of links, rather than the multi-point two-way system interaction based on connections. The AISAS model is still fundamentally based on advertising to generate Attention, a linear one-way marketing communication process, and a behavioral consumption process. In fact, Share and experience sharing are becoming the source of consumption in the real sense. The parameters of AISAS are depicted in Table 1.

Given the time point $t$ and $t-1$, railway service enterprises' impact on early $\mathrm{O} 2 \mathrm{O}$ user phase from $O$ to $t$ is defined as

$H T_{i}=S_{A A / B / D / D B A}$

and the cumulated impact from $O$ to $t$ is calculated as

$H T_{i-1}=S_{A / B / C / C B A}$

Therefore, the number of users in different mode between $t$ and $t-1$ is

$\Delta H T=H T_{i}-H T_{i-1}=S_{C / D / D C}$

The AISAS clustering centers based on K-means method is

$H T_{i}=\alpha_{0}+\alpha_{1} \cdot H T_{i-1}+f(T T, F L)$

\section{Portrait results}

In the model, the railway service company users can be abstracted into a topological graph $G(V, E)$, where $V$ represents the set of all nodes (including railway service company
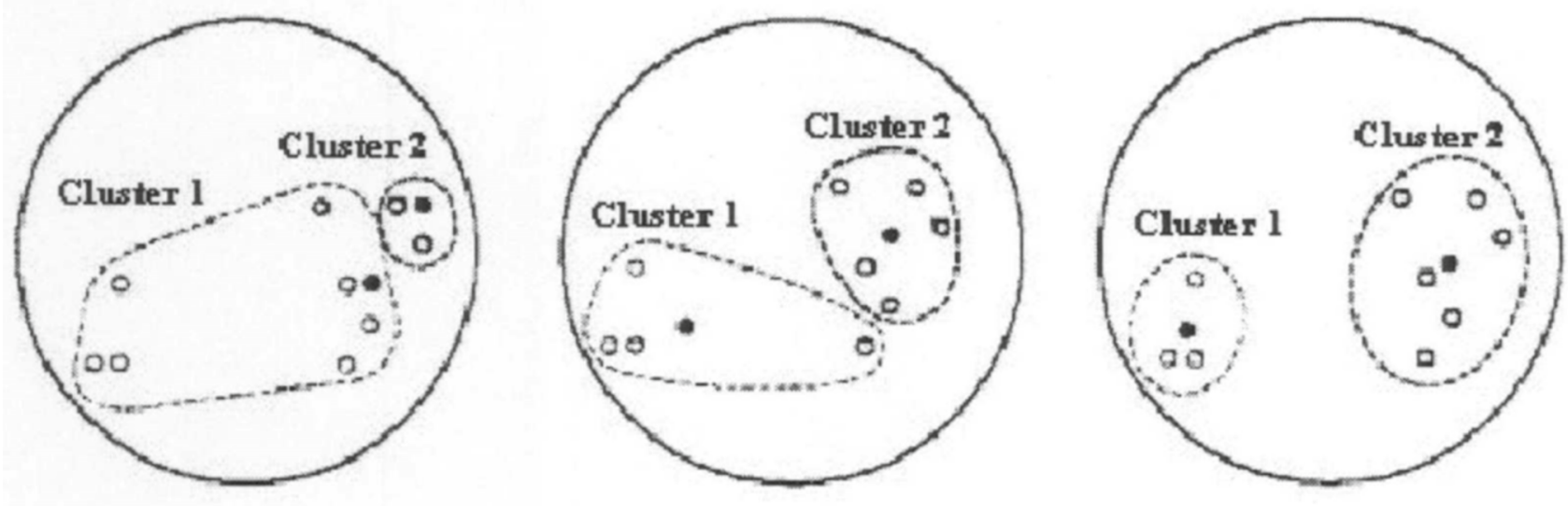

Fig. 2 The diagram of K-means algorithm 
Table 1 The parameters of AISAS

\begin{tabular}{ll}
\hline Parameters & Implication \\
\hline TT & The number of offline users serviced by railway service enterprises \\
FL & The quantity of railway service enterprises \\
HT & The number of online users serviced by railway service enterprises \\
$T$ & Time point of calculation \\
$t-1$ & Time point of calculation before $t$ \\
$\mathrm{HT}_{i}$ & The number of online users serviced by railway service enterprises \\
& during time point $O$ to $t$ \\
$\mathrm{HT}_{i-1}$ & The number of online users serviced by railway service enterprises \\
$\Delta \mathrm{HT}$ & during time point $O$ to $t-1$ \\
$\alpha_{0}$ & The number of users in different mode between $t$ and $t-1$ \\
$\alpha_{1}$ & Railway service enterprises' impact on early $\mathrm{O} 2 \mathrm{O}$ user phase \\
$\alpha_{2}$ & The coefficient of $H T_{i-1}$ which is [0,1] \\
\hline
\end{tabular}

and users and alternative points), $E$ represents the set of all arcs, and $G(V, E)$ represents the graph composed of all points and edges through certain connection relations. Next, given the demand of railway service company and the number of each demand: (1) the total number of $\kappa$ such demands, number $k=1,2, \ldots, \kappa$, the set of all demands is $\kappa$; (2) the size of the $\kappa$ th demand is $h^{k}$, the online and offline are $o^{k}$ and $d^{k}$, respectively, $O(D)$ denotes the set of online and offline of all demands; (3) $w^{k}$ represents the importance of the $\kappa$ th demand. $l_{i j}$ denotes the edge between nodes $i$ and $j$, and whether the $\kappa$ th demand passes through. $l_{i j}$ is denoted by $x_{i j}^{k}$. In addition, the length of each edge in the graph is $c_{i j}$ and the maximum number of visits allowed by the edge is $u_{i j}$. The number of modes placed at each node is less than $p$. The objective function is to minimize the total cost.

$$
\min \sum_{k \in K} \sum_{i \in V} \sum_{j \in V} c_{i j} x_{i j}^{k} h^{k} w^{k}
$$

Subject to

$\sum_{j \in V} x_{o^{k} j}^{k}=1, \quad \forall k \in K$

$\sum_{i \in V} x_{i d^{k}}^{k}=1, \quad \forall k \in K$

$\sum_{j \in V / O} x_{i j}^{k}=\sum_{j \in V / D} x_{j i}^{k} \quad \forall i \in V /\{O \cup D\}, k \in K$

$\sum_{k \in K} x_{i j}^{k} h^{k} \leq u_{i j}, \quad \forall i \in V, j \in V$

$$
f\left(x_{i j}^{k}\right) \leq n \quad \forall j \in V
$$

Table 2 The center of cluster

\begin{tabular}{llll}
\hline Mode & $\begin{array}{l}\text { O2O } \\
\text { expense/10,000 }\end{array}$ & $\begin{array}{l}\text { Disposable } \\
\text { income/10,000 }\end{array}$ & $\begin{array}{l}\text { Personal } \\
\text { income/10,000 }\end{array}$ \\
\hline SBSO & 0.68 & 10 & 36.5 \\
CCSO & 1.61 & 12.1 & 28.2 \\
SBCO & 3.2 & 8.6 & 22 \\
CCCO & 4.1 & 10.3 & 28 \\
\hline
\end{tabular}

Table 3 The distribution of different mode

\begin{tabular}{lllll}
\hline & SBSO & CCSO & SBCO & CCCO \\
\hline Number of samples & 2860 & 3507 & 5032 & 5344 \\
Rate $(\%)$ & 17.7 & 26.8 & 29.1 & 26.4 \\
\hline
\end{tabular}

Table 4 The results of cluster

\begin{tabular}{lllll}
\hline & $\begin{array}{l}\text { Inner cluster } \\
\text { distance }\end{array}$ & $\begin{array}{l}\text { Cross cluster } \\
\text { distance }\end{array}$ & $V$ & Accuracy \\
\hline$K$ means & 0.041 & 0.432 & 0.079 & $88.4 \%$ \\
\hline
\end{tabular}

$x_{i j}^{k}=\{0,1\} \quad \forall k \in K, i \in V, j \in V$

Constraints (9) and (10) denote that each user demand has and has only one online and offline, respectively. Constraint (11) is a user access balance constraint indicating that each user demand has only one online and offline preference. Constraint (12) is the user access constraint for each arc. Constraint (13) is the user access constraint for each mode. The function $f\left(x_{i j}^{k}\right)$ denotes the number of nonrepeating endpoints of the access demand through node $j$. Let the set $D_{j}$ store all the endpoints of access demands 
that pass through $j$. First calculate $x_{i j}^{k} d^{k}$ and store it into the set $D_{j}$ if $x_{i j}^{k} d^{k}$ is not equal to 0 . Delete the duplicate items in $D_{j}$ to get $D_{j}^{\prime}$, and the number of elements in $D_{j}^{\prime}$ is $f\left(x_{i j}^{k}\right)$. Constraint (14) indicates that $x_{i j}^{k}$ is a $0-1$ variable.

In this paper, the clustering centers were established when $K=4$, which represent the four clusters. The details were shown in Tables 2 and 3.

The effect of $K$-means algorithm was evaluated by supervision and non-supervision method, respectively. The results were shown in Table 4.

The portrait results were shown in Table 5.

Obviously, due to the lack of experience and foundation of self-build/self-operate, the companies tend to bring weaker results with the same effort as third-party companies. Based on the above background, the study assumes that there is a railway service company in the market that wants to change its $\mathrm{O} 2 \mathrm{O}$ supply chain service, and it is faced with the decision of building an $\mathrm{O} 2 \mathrm{O}$ supply chain service platform (self-built or entrusted with a third party) and operating model (self-operated or entrusted with a third party). As a result, the enterprise is faced with four choices: self-build and self-operate, commission build and self-operate, selfbuild and commission operate, and commission build and commission operate.

\section{Modeling, solution and analysis}

\section{SBSO, mode1}

When the railway service company (A) chooses to build its own supply chain online platform and operate itself, it needs to decide the degree $(\theta)$ of effort to build the platform, and the corresponding cost is $k_{1} \theta^{2} / 2$, at this time, because the platform only has the ability to integrate merchants and customers, and display products/services Such basic functions cannot bring more drainage effects. Therefore, the customer group coverage under the self-built mode is $(\theta)$; because the enterprise chooses to operate by itself, the enterprise needs to decide the degree of self-operation effort $e$, and the corresponding cost is $k_{2} \theta^{2} / 2$, the drainage effect is $\alpha e$, and now the profit function of the enterprise can be expressed as:

$\max \pi_{A}(\theta, e)=(\theta+\alpha e) p-\frac{k_{1} \theta^{2}}{2}-\frac{k_{2} e^{2}}{2}$

In the above formula, the total revenue of the first term $(\theta+\alpha e)$ is the number of customers, $p$ is the revenue per customer), the second term is the cost of platform establishment, and the third one is the operating cost. To maximize $\pi_{A}(\theta, e)$, let $\pi_{A}(\theta, e)=0$ to get its partial derivation.

$\left\{\begin{array}{l}\frac{\partial \pi_{A}(\theta, e)}{\partial \theta}=p-k_{1} \theta=0 \\ \frac{\partial \pi_{A}(\theta, e)}{\partial e}=\alpha p-k_{2} e=0\end{array}\right.$

The result is

$\left\{\begin{array}{l}\theta^{*}=\frac{p}{k_{1}} \\ e^{*}=\frac{\alpha p}{k_{2}}\end{array}\right.$

Put $\left(\theta^{*}, e^{*}\right)$ into $\pi_{A}(\theta, e)$, we get

$\pi_{A}\left(\theta^{*}, e^{*}\right)=\frac{p^{2}}{2 k_{1}}+\frac{\alpha^{2} p^{2}}{2 k_{2}}$

\section{CCSO, mode 2}

When a railway service company chooses to entrust a thirdparty company (B) to build a supply chain online platform and operate it itself, just like the model, A needs to decide
Table 5 The portrait of different mode

\begin{tabular}{|c|c|c|c|c|c|c|}
\hline O2O mode & $\begin{array}{l}\text { Mode and user } \\
\text { number }\end{array}$ & $R^{2}$ & $\begin{array}{l}\text { AISAS } \\
\text { parameter }\end{array}$ & $\begin{array}{l}\text { Association } \\
\text { coefficient }\end{array}$ & $T$ Statistic & Probability \\
\hline \multirow[t]{3}{*}{ SBSO } & \multirow[t]{3}{*}{0.992} & \multirow[t]{3}{*}{0.989} & FL & 0.015 & 2.689 & 0.011 \\
\hline & & & $\mathrm{HT}_{i-1}$ & 0.832 & 15.769 & 0.000 \\
\hline & & & $\alpha_{0}$ & 13.167 & 2.101 & 0.042 \\
\hline \multirow[t]{3}{*}{ CCSO } & \multirow[t]{3}{*}{0.945} & \multirow[t]{3}{*}{0.998} & FL & 0.280 & 4.899 & 0.000 \\
\hline & & & $\mathrm{HT}_{i-1}$ & 0.874 & 35.309 & 0.000 \\
\hline & & & $\alpha_{0}$ & -813.002 & -3.619 & 0.001 \\
\hline \multirow[t]{3}{*}{ SBCO } & \multirow[t]{3}{*}{0.971} & \multirow[t]{3}{*}{0.999} & FL & 0.210 & 1.531 & 0.134 \\
\hline & & & $\mathrm{HT}_{i-1}$ & 0.916 & 19.761 & 0.000 \\
\hline & & & $\alpha_{0}$ & -2279.52 & -1.431 & 0.159 \\
\hline \multirow[t]{3}{*}{$\mathrm{CCCO}$} & \multirow[t]{3}{*}{0.995} & \multirow[t]{3}{*}{0.998} & FL & -0.213 & -2.481 & 0.016 \\
\hline & & & $\mathrm{HT}_{i-1}$ & 1.048 & 115.441 & 0.000 \\
\hline & & & $\alpha_{0}$ & -19.138 & -0.791 & 0.433 \\
\hline
\end{tabular}


the degree of self-operation effort $e$, Since the construction of the supply chain online platform is entrusted to a thirdparty company, A needs to make a decision to pay B's platform construction costs $w_{1}\left(w_{1} \leq w_{1}<\overline{w_{1}}\right)$, and $\mathrm{B}$ needs the effort of making a decision-making platform $\theta$ (A stipulates that the effect of company B's construction platform should be no worse than the effect of A's self-built, that is $\theta \geq p /(1+\eta) k$, and the costs accordingly is $k_{3} \theta^{2} / 2\left(k_{3}<k_{1}\right)$. At this time, because B has the corresponding foundation and can bring more drainage effects, the customer group coverage under the entrusted third-party enterprise construction model $(1+\eta) \theta$, therefore, the profit function of an enterprise can be expressed as:

$$
\begin{array}{ll}
\max & \underset{w_{1} \leq w_{1}<\overline{w_{1}}}{\pi_{A}}\left(w_{1}, e\right)=[(1+\eta) \theta+\alpha e] p-w_{1}-\frac{k_{2} e^{2}}{2} \\
\text { s.t. } & \pi_{B}(\theta)=w_{1}-\frac{k_{3} \theta^{2}}{2} \\
& \pi_{(1+\eta) k_{1}} \\
& \pi_{B}\left(\theta^{*}\right) \geq 0
\end{array}
$$

In the objective function above, the first item is total revenue, the second item is the transfer payment for entrusting a third-party enterprise to build the platform, and the third item is the operating cost. Enterprise A needs to decide the size of the transfer payment and the degree of operational effort. And enterprise B needs to decide to build a platform, and one of the prerequisites for enterprise $B$ to accept enterprise A's commission is that enterprise B needs to obtain non-negative income. To maximize $\pi_{B}(\theta)$, We have the derivative of $\pi_{B}(\theta): \frac{d \pi_{B}(\theta)}{d \theta}=-k_{3} \theta<0$. And, $\theta^{*}=\frac{p}{(1+\eta) k_{1}}$, put $\theta^{*}$ into $\pi_{B}(\theta), \pi_{B}\left(\theta^{*}\right)=w_{1}-\frac{k_{3} p^{2}}{2(1+\eta)^{2} k_{1}^{2}}$ Since $\pi_{B}\left(\theta^{*}\right) \geq 0$, there is $w_{1} \geq \frac{k_{3} p^{2}}{2(1+\eta)^{2} k_{1}^{2}}$. Put $\theta^{*}$ into $\pi_{A}\left(w_{1}, e\right)$, we have $\pi_{A}\left(w_{1}, e\right)=\frac{p^{2}}{k_{1}}+\alpha e p-w_{1}-\frac{k_{2} e^{2}}{2}$ To maximize $\pi_{A}\left(w_{1}, e\right)$, we have the partial derivation of $\pi_{A}\left(w_{1}, e\right)$ :

$$
\left\{\begin{array}{c}
\frac{\partial \pi_{A}\left(w_{1}, e\right)}{\partial w_{1}}=-1<0 \\
\frac{\partial \pi_{A}\left(w_{1}, e\right)}{\partial e}=\alpha p-k_{2} e=0
\end{array}\right.
$$

And the result is

$$
\left\{\begin{array}{c}
w_{1}^{*}=\min \left(\underline{w_{1}}, \frac{k_{3} p^{2}}{2(1+\eta)^{2} k_{1}^{2}}\right) \\
e^{*}=\frac{\alpha p}{k_{2}}
\end{array}\right.
$$

We discuss the results in three situations.

$$
\begin{aligned}
& \text { 1. when } \frac{k_{3} p^{2}}{2(1+\eta)^{2} k_{1}^{2}} \leq \underline{w_{1}}, \quad w_{1}^{*}=\underline{w_{1}}, \quad \text { we obtain } \\
& \pi_{A}\left(w_{1}^{*}, e^{*}\right)=\frac{p^{2}}{k_{1}}+\frac{\alpha^{2} p^{2}}{2 k_{2}}-\underline{w_{1}} ;
\end{aligned}
$$

2. when $\quad w_{1} \leq \frac{k_{3} p^{2}}{2(1+\eta)^{2} k_{1}^{2}}<\overline{w_{1}}, \quad w_{1}^{*}=\frac{k_{3} p^{2}}{2(1+\eta)^{2} k_{1}^{2}}$, we get $\pi_{A}\left(w_{1}^{*}, e^{*}\right)=\frac{p^{2}}{k_{1}}+\frac{\alpha^{2} p^{2}}{2 k_{2}}-\frac{k_{3} p^{2}}{2(1+\eta)^{2} k_{1}^{2}} ;$

3. if $\overline{w_{1}} \leq \frac{k_{3} p^{2}}{2(1+\eta)^{2} k_{1}^{2}}$, since $\pi_{B}\left(\theta^{*}\right)<0$, no solution.

\section{SBCO, mode3}

When a railway service company chooses to build its own supply chain online platform and entrusts a third-party company to operate it, as in mode1, A needs to decide how hard it is to build the platform $\theta$, since platform operation is entrusted to a third-party company, A needs to make a decision to pay B's operating expenses $w_{2}\left(w_{2} \leq w_{2}<\overline{w_{2}}\right)$, and $\mathrm{B}$ needs to decide its operating effort $e$ (enterprise A stipulates that the effect of enterprise B's operation platform should be no worse than the effect of A's self-operation, that is $\left.e \geq \alpha^{2} p / \beta k_{2}\right)$, the cost is $k_{4} e^{2} / 2\left(k_{4}<k_{2}\right)$ accordingly. $\mathrm{B}$ has the corresponding operating experience which can bring more drainage effects, therefore, the drainage effect under the entrusted third-party enterprise operation model is $\beta e$ $(\beta>\alpha)$. At this time, the profit function of the firm can be expressed as

$$
\begin{array}{ll}
\max & \underset{w_{2} \leq w_{2}<\overline{w_{2}}}{\pi_{A}}\left(\theta, w_{2}\right)=(\theta+\beta e) p-\frac{k_{1} \theta^{2}}{2}-w_{2} \\
\text { s.t. } & \pi_{B}(e)=w_{2}-\frac{k_{4} e^{2}}{2} \\
& \pi^{2} \frac{\alpha^{2} p}{\beta k_{2}} \\
& \pi_{B}\left(e^{*}\right) \geq 0
\end{array}
$$

In the objective function above, the first term is total revenue, the second one is the cost of building the platform, and the third is the transfer payment for entrusting a third-party enterprise to operate on its behalf. Enterprise A needs to decide the degree of effort to build the platform and the size of transfer payment. And enterprise B needs to decide the degree of effort in operation, and one of the prerequisites for enterprise B to accept enterprise A's commission is that enterprise $\mathrm{B}$ needs to obtain non-negative income. To maximize $\pi_{B}(e)$, we have the derivation of $\pi_{B}(e), \frac{d \pi_{B}(e)}{d e}=-k_{4} e<0$, then $e^{*}=\frac{\alpha^{2} p}{\beta k_{2}}$, put $e^{*}$ into $\pi_{B}(e), \pi_{B}\left(e^{*}\right)=w_{2}-\frac{k_{4} \alpha^{4} p^{2}}{2 \beta^{2} k_{2}^{2}}$. Since $\pi_{B}\left(e^{*}\right) \geq 0, w_{2} \geq \frac{k_{4} \alpha^{4} p^{2}}{2 \beta^{2} k_{2}^{2}}$, put $e^{*}$ into $\pi_{A}\left(\theta, w_{2}\right)$, we get $\pi_{A}\left(\theta, w_{2}\right)=\theta p+\frac{\alpha^{2} p^{2}}{k_{2}}-\frac{k_{1} \theta^{2}}{2}-w_{2}$. Maximize $\pi_{A}\left(\theta, w_{2}\right)$, we have the partial derivation of $\pi_{A}\left(\theta, w_{2}\right)$,

$$
\left\{\begin{array}{c}
\frac{\partial \pi_{A}\left(\theta, w_{2}\right)}{\partial \theta}=p-k_{1} \theta=0 \\
\frac{\partial \pi_{A}\left(\theta, w_{2}\right)}{\partial w_{2}}=-1<0
\end{array}\right.
$$

Then 


$$
\left\{\begin{array}{c}
\theta^{*}=\frac{p}{k_{1}} \\
w_{2}^{*}=\min \left(\underline{w_{2}}, \frac{k_{4} \alpha^{4} p^{2}}{2 \beta^{2} k_{2}^{2}}\right)
\end{array}\right.
$$

There are also three situations in it,

1. when $\frac{k_{4} \alpha^{4} p^{2}}{2 \beta^{2} k_{2}^{2}} \leq \underline{w_{2}}, w_{2}^{*}=\underline{w_{2}}, \pi_{A}\left(\theta^{*}, w_{2}^{*}\right)=\frac{p^{2}}{2 k_{1}}+\frac{\alpha^{2} p^{2}}{k_{2}}-\underline{w_{2}}$ ;

2. wh e n $\quad w_{2} \leq \frac{k_{4} \alpha^{4} p^{2}}{2 \beta^{2} k_{2}^{2}}<\overline{w_{2}}, \quad w_{2}^{*}=\frac{k_{4} \alpha^{4} p^{2}}{2 \beta^{2} k_{2}^{2}}$, $\pi_{A}\left(\theta^{*}, w_{2}^{*}\right)=\frac{p^{2}}{2 k_{1}}+\frac{\alpha^{2} p^{2}}{k_{2}}-\frac{k_{4} \alpha^{4} p^{2}}{2 \beta^{2} k_{2}^{2}}$

3. when $\overline{w_{2}} \leq \frac{k_{4} \alpha^{4} p^{2}}{2 \beta^{2} k_{2}^{2}}$, since $\pi_{B}\left(e^{*}\right)<0$, thus, there is no solution.

\section{CCCO, mode4}

When the railway service company chooses to outsource all the work, A only needs to decide how much to pay to B, the amount is represented with $w(\underline{w} \leq w<\bar{w})$, and $\mathrm{B}$ needs to decide the efforts degree $\theta$ of platform construction and the platform operation $e$. The profit revenue function is expressed as

$$
\begin{array}{ll}
\max & \underset{w \leq w<\bar{w}}{\pi_{A}}(w)=[(1+\eta) \theta+\beta e] p-w \\
\text { s.t. } & \pi_{B} \quad(\theta, e)=w-\frac{k_{3} \theta^{2}}{2}-\frac{k_{4} e^{2}}{2} \\
& \pi_{\frac{p}{(1+\eta) k_{1}}} \\
e \geq \frac{\alpha^{2} p}{\beta k_{2}} & \pi_{B}\left(\theta^{*}, e^{*}\right) \geq 0
\end{array}
$$

Since A entrusts platform construction and operation to enterprise $\mathrm{B}$, the above objective function contains only two items. The first item is the total revenue, and the second item is the transfer payment for entrusting a third-party enterprise to build the platform and operate it. Enterprise A needs to decide the size of the transfer payment. And enterprise B needs the effort of decision-making platform construction and operation effort, and one of the prerequisites for enterprise $B$ to accept the commission of enterprise $A$ is that enterprise $\mathrm{B}$ needs to obtain non-negative income. To maximize $\pi_{B}(\theta, e)$, we need to have a partial derivation of $\pi_{B}(\theta, e)$ and let it equal 0 ,

$$
\left\{\begin{array}{l}
\frac{\partial \pi_{B}(\theta, e)}{\partial \theta}=-k_{3} \theta<0 \\
\frac{\partial \pi_{B}(\theta, e)}{\partial e}=-k_{4} e<0
\end{array}\right.
$$

Then $\left\{\begin{array}{c}\theta^{*}=\frac{p}{(1+\eta) k_{1}} \\ e^{*}=\frac{\alpha^{2} p}{\beta k_{2}}\end{array}\right.$

Put $\left(\theta^{*}, e^{*}\right) \quad$ in t o $\quad \pi_{B}(\theta, e), \quad$ th e n $\pi_{B}\left(\theta^{*}, e^{*}\right)=w-\frac{k_{3} p^{2}}{2(1+\eta)^{2} k_{1}^{2}}-\frac{k_{4} \alpha^{4} p^{2}}{2 \beta^{2} k_{2}^{2}}$. Since $\pi_{B}\left(\theta^{*}, e^{*}\right) \geq 0$, therefore, $w \geq \frac{k_{3} p^{2}}{2(1+\eta)^{2} k_{1}^{2}}+\frac{k_{4} \alpha^{4} p^{2}}{2 \beta^{2} k_{2}^{2}}$;Put $\left(\theta^{*}, e^{*}\right)$ into $\pi_{A}(w)$ ,$\pi_{A}(w)=\frac{p^{2}}{k_{1}}+\frac{\alpha^{2} p^{2}}{k_{2}}-w$; Maximize $\pi_{A}(w)$, we have the derivation of $\quad \pi_{A}(w), \quad$ ge t $\quad \frac{d \pi_{A}(w)}{d w}=-1<0$; $w^{*}=\min \left(\underline{w}, \frac{k_{3} p^{2}}{2(1+\eta)^{2} k_{1}^{2}}+\frac{k_{4} \alpha^{4} p^{2}}{2 \beta^{2} k_{2}^{2}}\right)$.

There are 3 situations:

1. when $\frac{k_{3} p^{2}}{2(1+\eta)^{2} k_{1}^{2}}+\frac{k_{4} \alpha^{4} p^{2}}{2 \beta^{2} k_{2}^{2}} \leq \underline{w}, w^{*}=\underline{w}$, we obtain $\pi_{A}\left(w^{*}\right)=\frac{p^{2}}{k_{1}}+\frac{\alpha^{2} p^{2}}{k_{2}}-\underline{w}$;

2. when $\underline{w} \leq \frac{k_{3} p^{2}}{2(1+\eta)^{2} k_{1}^{2}}+\frac{\overline{k_{4}} \alpha^{4} p^{2}}{2 \beta^{2} k_{2}^{2}}<\bar{w}, w^{*}=\frac{k_{3} p^{2}}{2(1+\eta)^{2} k_{1}^{2}}+\frac{k_{4} \alpha^{4} p^{2}}{2 \beta^{2} k_{2}^{2}}$; we get $\pi_{A}\left(w^{*}\right)=\frac{p^{2}}{k_{1}}+\frac{\alpha^{2} p^{2}}{k_{2}}-\frac{k_{3} p^{2}}{2(1+\eta)^{2} k_{1}^{2}}-\frac{k_{4} \alpha^{4} p^{2}}{2 \beta^{2} k_{2}^{2}}$;

3. $\bar{w} \leq \frac{k_{3} p^{2}}{2(1+\eta)^{2} k_{1}^{2}}+\frac{k_{4} \alpha^{4} p^{2}}{2 \beta^{2} k_{2}^{2}}$, since $\pi_{B}\left(\theta^{*}, e^{*}\right)<0$, there is no solution.

\section{Analysis of the four modes}

The four modes are modeled and solved above. Now we compare the four modes and draws corresponding conclusions.

\section{Mode 1 vs mode 2}

Corollary 1: when $\underline{w_{1}} \geq \frac{p^{2}}{2 k_{1}}$ or $\overline{w_{1}} \leq \frac{k_{3} p^{2}}{2(1+\eta)^{2} k_{1}^{2}}$, Mode1 gives priority to Mode2; or else, Mode2 is better than Mode1.

Under Mode 1, the profit of enterprise A is: $\pi_{A}\left(\theta^{*}, e^{*}\right)=\frac{p^{2}}{2 k_{1}}+\frac{\alpha^{2} p^{2}}{2 k_{2}} ;$ In Mode2,

$\pi_{A}\left(w_{1}^{*}, e^{*}\right)= \begin{cases}\frac{p^{2}}{k_{1}}+\frac{\alpha^{2} p^{2}}{2 k_{2}}-\underline{w_{1},} & \frac{k_{3} p^{2}}{2(1+\eta)^{2} k_{1}^{2}} \leq \underline{w_{1}} \\ \frac{p^{2}}{k_{1}}+\frac{\alpha^{2} p^{2}}{2 k_{2}}-\frac{k_{3} p^{2}}{2(1+\eta)^{2} k_{1}^{2}}, & \underline{w_{1}} \leq \frac{k_{3} p^{2}}{2(1+\eta)^{2} k_{1}^{2}}<\overline{w_{1}} \\ \text { No value }, & \overline{w_{1}} \leq \frac{k_{3} p^{2}}{2(1+\eta)^{2} k_{1}^{2}}\end{cases}$

While $\frac{k_{3} p^{2}}{2(1+\eta)^{2} k_{1}^{2}} \leq \underline{w_{1}}, \pi_{A}\left(\theta^{*}, e^{*}\right)-\pi_{A}\left(w_{1}^{*}, e^{*}\right)=\underline{w_{1}}-\frac{p^{2}}{2 k_{1}}$, then $\underline{w_{1}}<\frac{p^{2}}{2 k_{1}}$, Mode 2 is better than Mode1; and when $w_{1} \geq \frac{p^{2}}{2 k_{1}}$, Mode1 is better than Mode2. When $w_{1} \leq \frac{k_{3} p^{2}}{2(1+\eta)^{2} k_{1}^{2}}<\overline{w_{1}}$, $\pi_{A}\left(\theta^{*}, e^{*}\right)-\pi_{A}\left(w_{1}^{*}, e^{*}\right)=\frac{p^{2}}{2 k_{1}}\left[\frac{k_{3}}{(1+\eta)^{2} k_{k}}-\overline{1]}<0\right.$, and Mode2 is better than Mode1. Whereas $\overline{w_{1}} \leq \frac{k_{3} p^{2}}{2(1+\eta)^{2} k_{1}^{2}}$, there is no value in 
Mode2, thus only one option for Mode1. And because of $k_{3}<k_{1}$, then $\frac{k_{3} p^{2}}{2(1+\eta)^{2} k_{1}^{2}}<\frac{p^{2}}{2 k_{1}}$ is constantly true, therefore, Corollary1 is approved.

The completion 1 shows that when firm A gives a large lower bound or a small upper bound on the platform construction budget, firm A will choose to build and operate its own platform rather than delegate the construction and operation of the platform. Specifically, when the lower limit of the platform construction budget given by firm A is large, firm B will only meet A's minimum requirements in terms of platform construction, but will receive a very high transfer payment from $\mathrm{A}$, which is uneconomical for $A$. When the upper limit of the platform construction budget given by firm A is small, firm B will undertake the platform construction work and will not receive positive revenue, and for this reason, firm $B$ is not likely to undertake the platform construction work.

\section{Mode 1 vs mode 3}

Corollary 2: When $\underline{w_{2}} \geq \frac{\alpha^{2} p^{2}}{2 k_{2}}$ or $\overline{w_{2}} \leq \frac{k_{4} \alpha^{4} p^{2}}{2 \beta^{2} k_{2}^{2}}$, Mode 1 is better than Mode3, otherwise, Mode3 is better.

Proof is sketchy because it is the same process as to prove Corollary 1.

Corollary 2 shows that when firm A gives a very large lower or very small upper bound on its operating budget, firm A will choose to build and operate its own operations rather than build and commission its own operations. Specifically, when firm A gives a large lower bound on its operating budget, firm B will only meet A's minimum requirements in terms of operations but receives a very high transfer payment from $\mathrm{A}$, which is uneconomical for A. When firm A gives a very small upper bound on its operating budget, firm B will take over operations and will not receive a positive return, and for this reason, firm B will not be able to take over operations.

\section{Mode 1 vs mode 4}

Corollary 3: when $\underline{w} \geq \frac{p^{2}}{2 k_{1}}+\frac{\alpha^{2} p^{2}}{2 k_{2}}$ or $\bar{w} \leq \frac{k_{3} p^{2}}{2(1+\eta)^{2} k_{1}^{2}}+\frac{k_{4} \alpha^{4} p^{2}}{2 \beta^{2} k_{2}^{2}}$, Mode1 is better, otherwise, is Mode4.

Proof is slightly, and the same reason of proof process.

Corollary 3 shows that when enterprise A gives a large lower or small upper budget for platform construction and operation, enterprise A will choose to build and operate its own platform instead of commissioning construction and operation. Specifically, when the lower limit of the platform construction and operation budget given by firm A is large, firm B will only meet A's minimum requirements in terms of platform construction and operation, but receive a high transfer payment from $\mathrm{A}$, which is uneconomical for A. When the upper limit of the platform construction and operation budget given by firm $\mathrm{A}$ is small, firm B will undertake the platform construction and operation work, but will not receive positive revenue. May undertake the construction and operation of the platform.

\section{Numerical simulation}

The four modes involve a large number of parameters, and it is very complicated to analyze them simultaneously.

Considered the reality, we select parameters as follow: $k_{1}=10, k_{2}=20, k_{3}=8, k_{4}=15, \eta=0.1, w_{1}=1, \overline{w_{1}}=10$, $w_{2}=1, \overline{w_{2}}=10, \underline{w}=2$ and $\bar{w}=18$. In addition, in terms of $\overline{\text { the }}$ fact that the operating capabilities of the partners and the nature of the platform's products have a greater impact on the final selection of the four models, we develop numerical examples to explore them in this section.

From Fig. 3, it can be seen that the optimal model is influenced by the nature of the platform operating product and the operating capacity of the partner. Figure 1(1) shows that when the operating capability of the partner is only slightly better than that of the railway service enterprise, Mode 1 is
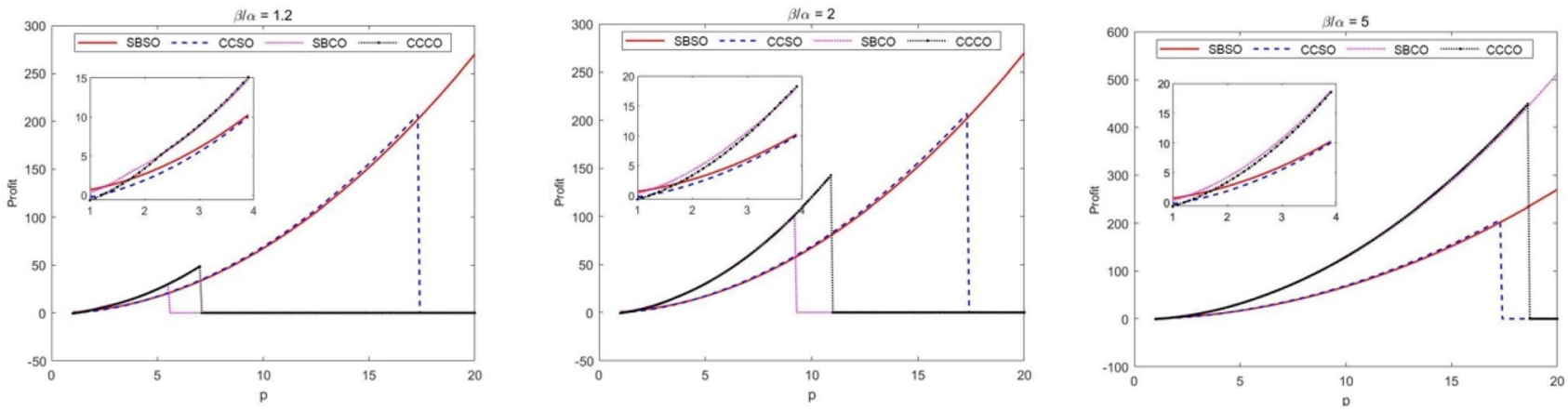

Fig. 3 Analysis of the impact of the partner's operating capabilities 
optimal if the revenue per passenger brought by the platform operating product is very low; if the revenue per passenger brought by the platform operating product is low, the effect of entrusted operation is better than self-operated operation; if the revenue per passenger brought by the platform operating product is high, Mode 2 is optimal; if the revenue per passenger brought by the platform operating product is low, the effect of entrusted operation is better than self-operated operation; if the revenue per passenger brought by the platform operating product is high, the effect of entrusted operation is better than self-operated operation. The revenue per customer reaches a very high level and Mode 1 is again the optimal choice. The reason for the above conclusion is that there is no cost budget constraint for self-build and self-operate, while the other three models are constrained by the upper and lower limits of cost budget. To enable rail service companies to achieve higher returns in the same situation, it is suggested that rail service companies can increase their commissioning budgets moderately. The conclusion of Fig. 1(2) is almost identical to Fig. 1(1) in that the revenue curves of mode 1 and mode 2 are identical, and the non-zero revenue curves of mode 3 and mode 4 are moderately extended. This implies that all other things being equal, the advantage of delegated operation becomes more pronounced as the operating capacity of the partner increases. Figure 1(3) confirms this point even more, and the comparison of the vertical coordinates between Fig. 1(3) and the two aforementioned sub-figures shows that all other conditions being equal, finding a partner with greater operational capacity can bring double the profit for the railway service enterprise.

In reality, a railway service company needs to decide on the range of products or services to be operated on the platform. For example, a railway service enterprise can provide only basic railway services including housekeeping and maintenance, or it can provide high-end railway services including study and tutoring, finance, etc. This sub-section examines the issue from the perspective of how exactly a railway service enterprise should ring-fence its scope of services.

There are three subgraphs in Fig. 4, and subgraph 2 (1) shows that when the product or service operated by the railway service enterprise's platform is more basic, the commissioning is better, and the optimal model changes from Mode 4 to Mode 3 as the partner's operational capacity increases. It should be noted that when the products or services operated by the platform are more basic, the railway service enterprise gains little. When the products or services operated by the platform of the railway service enterprise are moderate, entrusted self-operation is always better than self-built self-operation, and when the operating capacity of the partner is weak, the railway service enterprise will choose self-operation, and with the enhancement of the operating capacity of the partner, the revenue brought by entrusted operation will be better than self-operation, and entrusted entrustment is always better than self-built entrustment. When the products or services operated by the railway service enterprise platform are more advanced, the railway service enterprise will always choose mode one unless the partner's operational capability is superior.

\section{Findings}

Furthermore, the optimal strategy is influenced by the nature of the platform operation product and the operating capacity of the partner. When the operating capability of the partner is only a little better than that of the railway service enterprise, Mode 1 is optimal if the revenue per passenger brought by the platform operating product is very low; if the revenue per passenger brought by the platform operating product is low, the effect of entrusted operation is better than self-operation; if the revenue per passenger brought by the platform operating product is high, Mode 2 is optimal; once the revenue per passenger brought by the platform operating product reaches very low, the effect of entrusted operation is better than self-operation. At a high level, Model 1 is
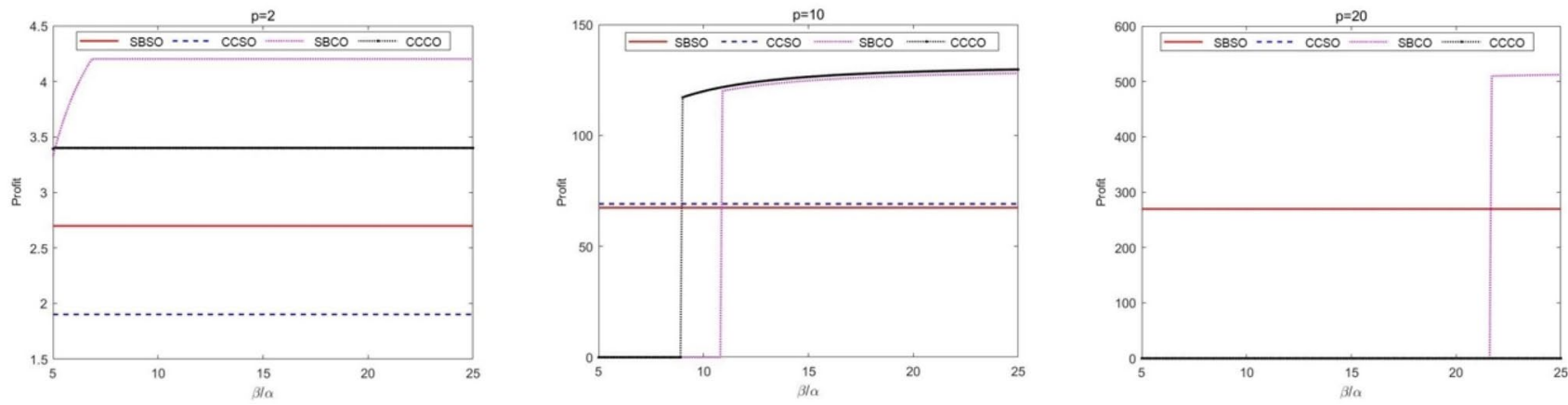

Fig. 4 Analysis of the impact of the nature of platform management products

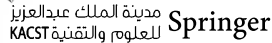


once again the optimal choice. And finding a partner with strong operational capability may be able to bring double the profits. From another point of view, when the products or services operated by the platform of railway service enterprises are relatively basic, the effect of entrusted operation is better, and as the operating capacity of the partner increases, the optimal mode changes from Mode 4 to Mode 3; when the products or services operated by the platform of railway service enterprises are moderate, entrusted self-operation is always better than self-constructed self-operation, and when the operating capacity of the partner is weak, railway service enterprises will choose self-operated operation. operations, as the partner's operational capability increases, the revenue generated by commissioning will be better than self-operation, and commissioning will always be better than self-constructed commissioning; when the products or services operated by the railway service company's platform are more advanced, the railway service company will always choose mode one unless the partner's operational capability is superior.

Establishing a platform successfully is the basis for railway service companies to meet the demands of $\mathrm{O} 2 \mathrm{O}$ supply chain services, therefore, railway service companies need to transform the traditional multi-level management model into a flat model which aims to ensure the normal operation of the entire $\mathrm{O} 2 \mathrm{O}$ supply chain service. According to the results, we find that when the lower budget limit given by the railway service enterprise is very large, the entrusted enterprise will only meet the minimum requirements of the railway service enterprise, but will receive a high transfer payment from the railway service enterprise, and the railway service enterprise will choose to build/operate itself; when the upper budget limit given by the railway service enterprise is very small, the entrusted enterprise refuses to undertake the relevant work because it will not receive positive income, and the railway service enterprise will choose to build/operate itself. Rail service companies can only choose to build/operate on their own. In other cases, delegated build/operate works better for the railway service enterprise. In this paper, the proposed model only considers the cost of $\mathrm{O} 2 \mathrm{O}$ platform construction. However, the influencing factors of $\mathrm{O} 2 \mathrm{O}$ platform establishment are diverse, in which the railway passage flow volume are important other than cost. Therefore, number of visitors may be considered as a factor to the model to help railway enterprises to make decision.

Acknowledgements This work was supported by MOE (Ministry of Education in China) Project of Humanities and Social Sciences (No. 20YJC630087), and Beijing Social Science Foundation (No. 19GLC072).

Open Access This article is licensed under a Creative Commons Attribution 4.0 International License, which permits use, sharing, adaptation, distribution and reproduction in any medium or format, as long as you give appropriate credit to the original author(s) and the source, provide a link to the Creative Commons licence, and indicate if changes were made. The images or other third party material in this article are included in the article's Creative Commons licence, unless indicated otherwise in a credit line to the material. If material is not included in the article's Creative Commons licence and your intended use is not permitted by statutory regulation or exceeds the permitted use, you will need to obtain permission directly from the copyright holder. To view a copy of this licence, visit http://creativecommons. org/licenses/by/4.0/.

\section{References}

1. He B, Gupta V, Mirchandani $\mathrm{P}$ (2021) Online selling through $\mathrm{O} 2 \mathrm{O}$ platform or on your own? Strategic implications for local Brickand-Mortar stores. Omega. https://doi.org/10.1016/j.omega.2021. 102424

2. Rampell A (2010) Why online2Offline commerce is a trillion dollar opportunity. Techcrunch. http://techcrunch.com/2010/08/07/ why-online2offline-commerce-is-a-trillion-dollar-opportunity

3. Fang Z (2015) Analysis of $\mathrm{O} 2 \mathrm{O}$ business model in supermarket retailing. Bus Econ (6): 89-90+123

4. Du Y, Tang Y (2014) Study on the development of O2O E-commerce platform of China from the perspective of offline service quality. Int J Bus Soc Sci 5(4):308-312

5. Lu C, Liu S (2016) Cultural tourism O2O business model innovation-a case study of CTrip. J Electron Commer Organ 14(2):16-31

6. Yu L (2018) Cloud storage-based personalized sports activity management in Internet plus $\mathrm{O} 2 \mathrm{O}$ sports community. Concurr Comput Pract Exp 30(24):1-10

7. Shen C, Chen M, Wang C (2019) Analyzing the trend of O2O commerce by bilingual text mining on social media. Comput Hum Behav 101:474-483

8. Zhang J, Liu F, Tang J, Li Y (2019) The online integrated order picking and delivery considering Pickers' learning effects for an O2O community supermarket. Transp Res Part E Log Transp Rev 123:180-199

9. Zhang P, Moon H (2015) A study on the effects of O2O commerce characteristics and consumer characteristics on trust, desire and behavioral intention in China. In: 2015 Korea Institute of trade winter Academic Conference. Korea Trade Research Association, pp 107-123

10. Won J, Kang H, Kim B (2017) The effect of food online-to-offline $(\mathrm{O} 2 \mathrm{O})$ service characteristics on customer beliefs using the technology acceptance model. Culin Sci Hos Res 23(7):97-111

11. Li H, Shen Q, Bart Y (2018) Local market characteristics and online-to-offline commerce: an empirical analysis of Groupon. Manage Sci 64(4):1860-1878

12. $\mathrm{Xu} \mathrm{T}$ (2017) Development analysis of $\mathrm{O} 2 \mathrm{O}$ model based on mobile electronic business. In: Proceedings of the Fourth International Forum on Decision Sciences. Springer, pp 507-516

13. Hui PYA (2019) Challenges of $\mathrm{O} 2 \mathrm{O}$ adoption from single channel model to closed-loop O2O in Hong Kong. Hong Kong Polytechnic University, Hong Kong

14. Xing X, Junxuan Z (2014) The study of O2O business model development strategy in SMEs. Int J Bus Soc Sci 5(9):296-299

15. Wan J, Jiang Q, Zhu Y (2016) Research on core essential elements for $\mathrm{O} 2 \mathrm{O}$ business model with ANP. Wuhan International Conference On E-Bisnis. In: Wuhan International Conference on e-Business. AISeL, pp 113-123

16. Gao F, Su X (2017) Omni channel retail operations with buyonline-and-pick-up-in-store. Manage Sci 63(8):2478-2492

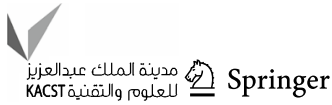


17. Mehra A, Kumar S, Raju JS (2018) Competitive strategies for brick-and-mortar stores to counter "showrooming." Manage Sci 64(7):3076-3090

18. Tsay A, Agrawal N (2004) Channel conflict and coordination in the e-commerce age. Prod Oper Manag 13(1):93-110

19. Ullrich K, Transchel S (2017) Demand-supply mismatches and stock market performance: a retailing perspective. Prod Oper Manag 26(8):1444-1462

20. Chocarro R, Cortiñas M, Villanueva ML (2013) Situational variables in online versus offline channel choice. Electron Commer Res Appl 12(5):347-361

21. Jain A, Bala R (2018) Differentiated or integrated: capacity and service level choice for differentiated products. Eur J Oper Res 266(3):1025-1037

22. Resta B, Gaiardelli P, Cavalieri S, Dotti S (2017) Enhancing the design and management of the product-service system supply chain: an application to the automotive sector. Serv Sci 9(4):302-314

23. Caggiano KE, Jackson PL, Muckstadt JA, Rappold JA (2007) Optimizing service parts inventory in a multiechelon, multi-item supply chain with time-based customer service-level agreements. Oper Res 55(2):303-318

24. Kim DJ (2012) An investigation of the effect of online consumer trust on expectation, satisfaction, and post-expectation. IseB 10(2):219-240

25. Arce-Urriza M, Cebollada J (2012) Private labels and national brands across online and offline channels. Manag Decis 50(10):1772-1789

Publisher's Note Springer Nature remains neutral with regard to jurisdictional claims in published maps and institutional affiliations. 